$\xi$

\title{
Availability comparison between three dissimilar photovoltaic configurations
}

\author{
Suleiman K ${ }^{1 *}$, Ibrahim Yusuf ${ }^{2}$, U. A. Ali1, A. D. Koko ${ }^{3}$, Saminu I. Bala ${ }^{2}$ \\ ${ }^{1}$ Department of Mathematics Federal University, Dutse, Nigeria \\ ${ }^{2}$ Department of Mathematical Sciences Bayero University, Kano, Nigeria \\ ${ }^{3}$ Department of Mathematics, Usmanu Danfodio University, Sokoto, Nigeria \\ *Corresponding author E-mail: kabiru.suleman@yahoo.ca
}

\begin{abstract}
The paper deals with availability comparison between three dissimilar photovoltaic configurations using Markov Birth-Death process and probabilistic approach. The configurations consist of four subsystems arranged in series-parallel with three possible states; working with full capacity, reduced capacity and failed. Through the transition diagrams, systems of differential equations are developed and solved recursively via probabilistic approach. Explicit expressions for steady-state availability are derived. Availability matrices for each subsystem have been developed to provide various performance values for different combinations of failure and repair rates of all subsystems. Furthermore, we compare the availability for the three configurations and find that configuration III is more reliable than system, I and II. The results have shown that the system availability increases with increase in redundant units. The results of this paper will enhance the system performance and useful for timely execution of proper maintenance improvement, decision, planning and optimization.
\end{abstract}

Keywords: Availability; Redundancy; Solar Photovoltaic System.

\section{Introduction}

The industrial and manufacturing systems comprise of large complex engineering systems arranged in series, parallel, or a combination of both. Some of these systems are solar photovoltaic, feeding, crushing, refining, steam generation, evaporation, crystallization, fertilizer plant, crystallization unit of a sugar plant, piston manufacturing plant, etc. Most of the world power generation systems use large generators and large distribution networks to provide energy to the consumers. In recent years, alternative energy sources such as photovoltaic, Eolic and biomass have gained ground. The study of photovoltaic (PV) energy has shown its technical and economic feasibility as an option to conventional systems. The reliability, availability and profit are the most important factors in any successful industries and manufacturing settings. Availability of an industrial system may be enhancing using highly reliable structural design of the system or subsystem of higher reliability. Improving the reliability and availability of system/subsystem, the production and associated profit will also increase. Increase in production lead to the increase of profit. This can be achieved to be maintaining reliability and availability at highest order. Many research results have been reported on the analysis and comparison of availability of the systems mentioned above. Khatab et al [6] have analyzed the Availability of k-out-of$\mathrm{n}$ : G systems with non identical components subject to repair priorities, Ke and Chu [7] performed computational comparisons of confidence intervals for the steady-state availability of a repairable system. Mokaddis et al.[9] performed comparative analysis between two unit cold standby and warm standby outdoor electric power systems in changing weather. Villava and Gazoli [12] presented the basic behavior of photovoltaic devices under different irradiance levels and also introduced a simple method to model and simulate the practical PV arrays. Wang et al.[13] performed Comparison of reliability and availability between four systems with warm standby components and standby switching failures. Wang and Chen [14] performed comparative analysis of availability between three systems with general repair times, reboot delay and switching failures. Wang et al.[15] performed comparative analysis of availability between two systems with warm standby units and different imperfect coverage. Yusuf [16] performed comparative analysis of some reliability characteristics between redundant systems requiring supporting units for their operation.

Although extensive research works exist within the field of mathematical modelling of photovoltaic system, there is a lack of quality-based availability modelling and performance evaluation of photovoltaic system in the reliability analysis. Mathematical model of the photovoltaic device is significantly valuable for studying the maximum power point tracking algorithms, conducting research about the dynamic performance of converters, and also for simulating photovoltaic components by using circuit simulators, (see, for instance, Abdulkadir et. Al. [1], Ajay et.al.[2], Bastidas et al. [3], Elhassan et al.[4], Enslin et. Al. [5], Mahmodian et al. [8], Mekhilef et al.[10]). Existing literature either ignores the impact of design on system performance or the effect of failure and service rate on performance of the photovoltaic system. Probabilistic models should be developed to address these issues. The contribution of this paper is of fourfold. First is to develop the explicit expressions for steady-state availability of the configurations. Second is to perform numerical investigation on the effect of system parameters (failure and repair rates) system availability. The third is to determine the effect of design on system performance. The remainder of this paper is organized as follows: Section 2 gives the description of the configurations. Section 3 gives the detail models formulation. Section 4 presents the numerical results 
and discussions. In the end, section 5 gives some concluding remarks.

\section{Description of the configurations}

In this paper, we considered three dissimilar solar photovoltaic configurations. Each configuration has four subsystems arranged in series-parallel. Configuration I have two PV ( $\mathrm{A}_{1}$ and $\left.\mathrm{A}_{2}\right)$ panel in active parallel as subsystem A, one MPPT as subsystem $\mathrm{B}$, one battery as subsystem $\mathrm{C}$ and one DC/AC inverter as subsystem D connected in series. Configuration II has three PV $\left(\mathrm{A}_{1}, \mathrm{~A}_{2}\right.$ and $\left.\mathrm{A}_{3}\right)$ panel in active parallel as subsystem A, one MPPT as subsystem $\mathrm{B}$, one battery as subsystem $\mathrm{C}$ and one $\mathrm{DC} / \mathrm{AC}$ inverter as subsystem D connected in series. Configuration III has four PV $\left(\mathrm{A}_{1}, \mathrm{~A}_{2}\right.$, $\mathrm{A}_{3}$ and $\mathrm{A}_{4}$ ) panel in active parallel as subsystem $\mathrm{A}$, one MPPT as subsystem $\mathrm{B}$, one battery as subsystem $\mathrm{C}$ and one $\mathrm{DC} / \mathrm{AC}$ inverter as subsystem $\mathrm{D}$ connected in series to produce an output. When unit $A_{1}$ or $A_{2}$ in subsystem $A$ fails with failure rate $\alpha_{1}$, it is sent for repair with service rate of $\beta_{1}$. The configuration works whenever subsystems A, B, C and D are working and failed when any of the subsystems A, B, C or D have failed. It is assumed in this study that the failure and repair rates of sub-system A (PV panel) be $\alpha_{1}$ and $\beta_{1}$ respectively; that of subsystem B (MPPT) be $\alpha_{2}$ and $\beta_{2}$, that of subsystem $C$ (Battery) be $\alpha_{3}$ and $\beta_{3}$ that of subsystem $D$ (Inverter) be $\alpha_{4}$ and $\beta_{4}$ respectively.

\section{Availability models formulations}

\subsection{Availability formulation for configuration I}

The following system linear differential equations associated with configuration I

$$
\begin{aligned}
& \mathrm{p}_{0}^{\prime}(\mathrm{t})=-\left(2 \alpha_{1}+\alpha_{2}+\alpha_{3}+\alpha_{4}\right) \mathrm{p}_{0}(\mathrm{t})+ \\
& \beta_{1} \mathrm{p}_{1}(\mathrm{t})+\beta_{2} \mathrm{p}_{3}(\mathrm{t})+\beta_{3} \mathrm{p}_{4}(\mathrm{t})+\beta_{4} \mathrm{p}_{5}(\mathrm{t}) \\
& \mathrm{p}_{1}^{\prime}(\mathrm{t})=-\left(\beta_{1}+\sum_{\mathrm{k}=1}^{4} \alpha_{\mathrm{k}}\right) \mathrm{p}_{1}(\mathrm{t})+2 \alpha_{1} \mathrm{p}_{0}(\mathrm{t})+ \\
& \beta_{1} \mathrm{p}_{2}(\mathrm{t})+\beta_{2} \mathrm{p}_{6}(\mathrm{t})+\beta_{3} \mathrm{p}_{7}(\mathrm{t})+\beta_{4} \mathrm{p}_{8}(\mathrm{t}) \\
& \mathrm{p}_{2}^{\prime}(\mathrm{t})=-\beta_{1} \mathrm{p}_{2}(\mathrm{t})+\alpha_{1} \mathrm{p}_{1}(\mathrm{t}) \\
& \mathrm{p}_{3}^{\prime}(\mathrm{t})=-\beta_{2} \mathrm{p}_{3}(\mathrm{t})+\alpha_{2} \mathrm{p}_{0}(\mathrm{t}) \\
& \mathrm{p}_{4}^{\prime}(\mathrm{t})=-\beta_{3} \mathrm{p}_{4}(\mathrm{t})+\alpha_{3} \mathrm{p}_{0}(\mathrm{t}) \\
& \mathrm{p}_{5}^{\prime}(\mathrm{t})=-\beta_{4} \mathrm{p}_{5}(\mathrm{t})+\alpha_{4} \mathrm{p}_{0}(\mathrm{t}) \\
& \mathrm{p}_{6}^{\prime}(\mathrm{t})=-\beta_{2} \mathrm{p}_{6}(\mathrm{t})+\alpha_{2} \mathrm{p}_{1}(\mathrm{t}) \\
& \sum_{\mathrm{i}=0}^{\prime}(\mathrm{t})=-\beta_{3} \mathrm{p}_{7}(\mathrm{t})+\alpha_{3} \mathrm{p}_{1}(\mathrm{t}) \\
& \mathrm{p}_{8}^{\prime}(\mathrm{t})=-\beta_{4} \mathrm{p}_{8}(\mathrm{t})+\alpha_{4} \mathrm{p}_{1}(\mathrm{t}) \\
& 8
\end{aligned}
$$

In steady state, the derivatives of states probabilities become zero.
The probability of operational states, namely, $\mathrm{p}_{0}(\mathrm{t})$ and $\mathrm{p}_{1}(\mathrm{t})$ are determined by using

solving equations (1) to (8) above and setting them to zero and using normalising condition (9).

The steady state availability $A_{V 1}(t)$ is summation of all working and reduced capacity states probabilities.

Thus

$$
\begin{aligned}
& \mathrm{A}_{\mathrm{V} 1}(\mathrm{t})=\mathrm{p}_{0}(\mathrm{t})+\mathrm{p}_{1}(\mathrm{t})=\frac{1+2 \mathrm{x}_{1}}{\Delta_{1}} \\
& \Delta_{1}=\left(1+2 \mathrm{x}_{1}+2 \mathrm{x}_{1}^{2}+\mathrm{x}_{2}+\mathrm{x}_{3}+\mathrm{x}_{4}+2 \mathrm{x}_{1} \mathrm{x}_{2}+2 \mathrm{x}_{1} \mathrm{x}_{3}+2 \mathrm{x}_{1} \mathrm{x}_{4}\right)
\end{aligned}
$$

\subsection{Availability formulation for configuration II}

The following system linear differential equations associated with configuration II

$$
p_{0}^{\prime}(t)=-\left(2 \alpha_{1}+\sum_{k=1}^{4} \alpha_{k}\right) p_{0}(t)+
$$

$\beta_{1} p_{1}(t)+\beta_{2} p_{6}(t)+\beta_{3} p_{4}(t)+\beta_{4} p_{5}(t)$

$\mathrm{p}_{1}^{\prime}(\mathrm{t})=-\left(\beta_{1}+\alpha_{1}+\sum_{\mathrm{k}=1}^{4} \alpha_{\mathrm{k}}\right) \mathrm{p}_{1}(\mathrm{t})+2 \alpha_{1} \mathrm{p}_{0}(\mathrm{t})+$

$\beta_{2} p_{8}(t)+\beta_{1} p_{2}(t)+\beta_{4} p_{9}(t)+\beta_{3} p_{7}(t)$

$p_{4}^{\prime}(t)=-\beta_{3} p_{4}(t)+\alpha_{3} p_{0}(t)$

$\mathrm{p}_{5}^{\prime}(\mathrm{t})=-\beta_{4} \mathrm{p}_{5}(\mathrm{t})+\alpha_{4} \mathrm{p}_{0}(\mathrm{t})$

$p_{6}^{\prime}(t)=-\beta_{2} p_{6}(t)+\alpha_{2} p_{0}(t)$

$\mathrm{p}_{7}^{\prime}(\mathrm{t})=-\beta_{3} \mathrm{p}_{7}(\mathrm{t})+\alpha_{3} \mathrm{p}_{1}(\mathrm{t})$

$\mathrm{p}_{8}^{\prime}(\mathrm{t})=-\beta_{2} \mathrm{p}_{8}(\mathrm{t})+\alpha_{2} \mathrm{p}_{1}(\mathrm{t})$

$\mathrm{p}_{9}^{\prime}(\mathrm{t})=-\beta_{4} \mathrm{p}_{9}(\mathrm{t})+\alpha_{4} \mathrm{p}_{1}(\mathrm{t})$

$p_{10}^{\prime}(t)=-\beta_{3} p_{10}(t)+\alpha_{3} p_{2}(t)$

$$
\mathrm{p}_{11}^{\prime}(\mathrm{t})=-\beta_{2} \mathrm{p}_{11}(\mathrm{t})+\alpha_{2} \mathrm{p}_{2}(\mathrm{t})
$$

$\mathrm{p}_{12}^{\prime}(\mathrm{t})=-\beta_{4} \mathrm{p}_{12}(\mathrm{t})+\alpha_{4} \mathrm{p}_{2}(\mathrm{t})$

The probability operational states, namely, $\mathrm{p}_{0}(\mathrm{t}), \mathrm{p}_{1}(\mathrm{t})$ and $\mathrm{p}_{2}(\mathrm{t})$ are determined by using normalizing condition below:

$\sum_{i=0}^{12} p_{i}(t)=1$

In steady state, the derivatives of states probabilities become zero. The probability of operational states, namely, $\mathrm{p}_{0}(\mathrm{t}), \mathrm{p}_{1}(\mathrm{t})$ and $\mathrm{p}_{2}(\mathrm{t})$ are determined by using solving equations (11) to (23) above and setting them to zero and using normalising condition (24). 
The steady state availability $\mathrm{A}_{\mathrm{V} 2}(\mathrm{t})$ is summation of all working and reduced capacity states probabilities. Thus

$$
\begin{aligned}
& A_{V 2}(t)=\sum_{m=0}^{2} p_{m}(t)=\frac{1+3 x_{1}+6 x_{1}^{2}}{\Delta_{2}+\Delta_{3}} \\
& \Delta_{2}=1+3 x_{1}+6 x_{1}^{2}+6 x_{1}^{3}+x_{2}+x_{3}+x_{4}+3 x_{1} x_{2} \\
& \Delta_{3}=3 x_{1} x_{3}+3 x_{1} x_{4}+6 x_{1}^{2} x_{2}+6 x_{1}^{2} x_{3}+6 x_{1}^{2} x_{4}
\end{aligned}
$$

\subsection{Availability formulation for configuration III}

The following system linear differential equations associated with configuration III

$$
\begin{aligned}
& \mathrm{p}_{0}^{\prime}(\mathrm{t})=-\left(3 \alpha_{1}+\sum_{\mathrm{k}=1}^{4} \alpha_{\mathrm{k}}\right) \mathrm{p}_{0}(\mathrm{t})+ \\
& \beta_{1} p_{1}(t)+\beta_{2} p_{5}(t)+\beta_{3} p_{6}(t)+\beta_{4} p_{7}(t) \\
& \mathrm{p}_{1}^{\prime}(\mathrm{t})=-\left(\beta_{1}+2 \alpha_{1}+\sum_{\mathrm{k}=1}^{4} \alpha_{\mathrm{k}}\right) \mathrm{p}_{1}(\mathrm{t})+ \\
& 4 \alpha_{1} p_{0}(t)+\beta_{1} p_{2}(t)+\beta_{2} p_{8}(t)+\beta_{3} p_{9}(t)+\beta_{4} p_{10}(t) \\
& \mathrm{p}_{2}^{\prime}(\mathrm{t})=-\left(\beta_{1}+\alpha_{1}+\sum_{\mathrm{k}=1}^{4} \alpha_{\mathrm{k}}\right) \mathrm{p}_{2}(\mathrm{t})+ \\
& 3 \alpha_{1} p_{1}(t)+\beta_{1} p_{3}+\beta_{2} p_{11}(t)+\beta_{3} p_{12}(t)+\beta_{4} p_{13}(t) \\
& p_{3}^{\prime}(t)=-\left(\beta_{1}+\sum_{k=1}^{4} \alpha_{k}\right) p_{3}(t)+2 \alpha_{1} p_{2}(t)+ \\
& \beta_{2} \mathrm{p}_{14}(\mathrm{t})+\beta_{3} \mathrm{p}_{15}(\mathrm{t})+\beta_{4} \mathrm{p}_{16}(\mathrm{t})+\beta_{1} \mathrm{p}_{4}(\mathrm{t}) \\
& \mathrm{p}_{4}^{\prime}(\mathrm{t})=-\beta_{1} \mathrm{p}_{4}(\mathrm{t})+\alpha_{1} \mathrm{p}_{3}(\mathrm{t}) \\
& \mathrm{p}_{5}^{\prime}(\mathrm{t})=-\beta_{2} \mathrm{p}_{5}(\mathrm{t})+\alpha_{2} \mathrm{p}_{0}(\mathrm{t}) \\
& \mathrm{p}_{6}(\mathrm{t})=-\beta_{3} \mathrm{p}_{6}(\mathrm{t})+\alpha_{3} \mathrm{p}_{0}(\mathrm{t}) \\
& \mathrm{p}_{7}^{\prime}(\mathrm{t})=-\beta_{4} \mathrm{p}_{7}(\mathrm{t})+\alpha_{4} \mathrm{p}_{0}(\mathrm{t}) \\
& \mathrm{p}_{8}^{\prime}(\mathrm{t})=-\beta_{2} \mathrm{p}_{8}(\mathrm{t})+\alpha_{2} \mathrm{p}_{1}(\mathrm{t}) \\
& \mathrm{p}_{9}^{\prime}(\mathrm{t})=-\beta_{3} \mathrm{p}_{9}(\mathrm{t})+\alpha_{3} \mathrm{p}_{1}(\mathrm{t}) \\
& \mathrm{p}_{10}(\mathrm{t})=-\beta_{4} \mathrm{p}_{10}(\mathrm{t})+\alpha_{4} \mathrm{p}_{1}(\mathrm{t}) \\
& p_{11}(t)=-\beta_{2} p_{11}(t)+\alpha_{2} p_{2}(t) \\
& p_{12}(t)=-\beta_{3} p_{12}(t)+\alpha_{3} p_{2}(t)
\end{aligned}
$$

$$
\begin{aligned}
& p_{13}^{\prime}(t)=-\beta_{4} p_{13}(t)+\alpha_{4} p_{2}(t) \\
& p_{14}^{\prime}(t)=-\beta_{2} p_{14}(t)+\alpha_{2} p_{3}(t) \\
& p_{15}^{\prime}(t)=-\beta_{3} p_{15}(t)+\alpha_{3} p_{3}(t) \\
& p_{16}^{\prime}(t)=-\beta_{4} p_{16}(t)+\alpha_{4} p_{3}(t)
\end{aligned}
$$

The probability operational states, namely, $\mathrm{p}_{0}(\mathrm{t}), \mathrm{p}_{1}(\mathrm{t}), \mathrm{p}_{2}(\mathrm{t})$ and ${ }^{p_{3}(t)}$ are determined by using normalizing condition below:

$$
\sum_{i=0}^{16} p_{i}(t)=1
$$

In steady state, the derivatives of states probabilities become zero. The probability of operational states, namely, $\mathrm{p}_{0}(\mathrm{t}), \mathrm{p}_{1}(\mathrm{t}), \mathrm{p}_{2}(\mathrm{t})$ and $\mathrm{p}_{3}(\mathrm{t})$ are determined by using solving equations (25) to (41) above and setting them to zero and using normalising condition (42).

The steady state availability $\mathrm{A}_{\mathrm{V} 3}(\mathrm{t})$ is summation of all working and reduced capacity states probabilities. Thus

$$
\mathrm{A}_{\mathrm{V} 3}(\mathrm{t})=\sum_{\mathrm{m}=0}^{3} \mathrm{p}_{\mathrm{m}}(\mathrm{t})=\frac{1+4 \mathrm{x}_{1}+12 \mathrm{x}_{1}^{2}+24 \mathrm{x}_{1}^{3}}{\Delta_{4}+\Delta_{5}}
$$

$$
\Delta_{4}=1+4 \mathrm{x}_{1}+12 \mathrm{x}_{1}^{2}+24 \mathrm{x}_{1}^{3}+
$$

$24 x_{1}^{4}+x_{2}+x_{3}+x_{4}+4 x_{1} x_{2}+4 x_{1} x_{3}$

$\Delta_{5}=4 \mathrm{x}_{1} \mathrm{x}_{4}+12 \mathrm{x}_{1}^{2} \mathrm{x}_{2}+$

$12 x_{1}^{2} x_{3}+12 x_{1}^{2} x_{4}+24 x_{1}^{3} x_{2}+24 x_{1}^{3} x_{3}+24 x_{1}^{3} x_{4}$

Where

$x_{j}=\frac{\alpha_{j}}{\beta_{j}}, j=1,2,3,4$

\section{Results and discussion}

The purpose of this section is to present specific graphical comparisons for the availability. Microsoft excel is used to compare three configurations in terms of their availability. Block bar chart are plotted to illustrate how each configuration behave with respect to failure rate For the purpose of graphical example, the following set of parameter values are used:

$$
\begin{aligned}
& \beta_{1}=0.6, \alpha_{2}=0.01 \beta_{2}=0.1, \alpha_{3}=0.02, \beta_{3}=0.2, \alpha_{4}=0.002, \\
& \beta_{4}=0.2
\end{aligned}
$$




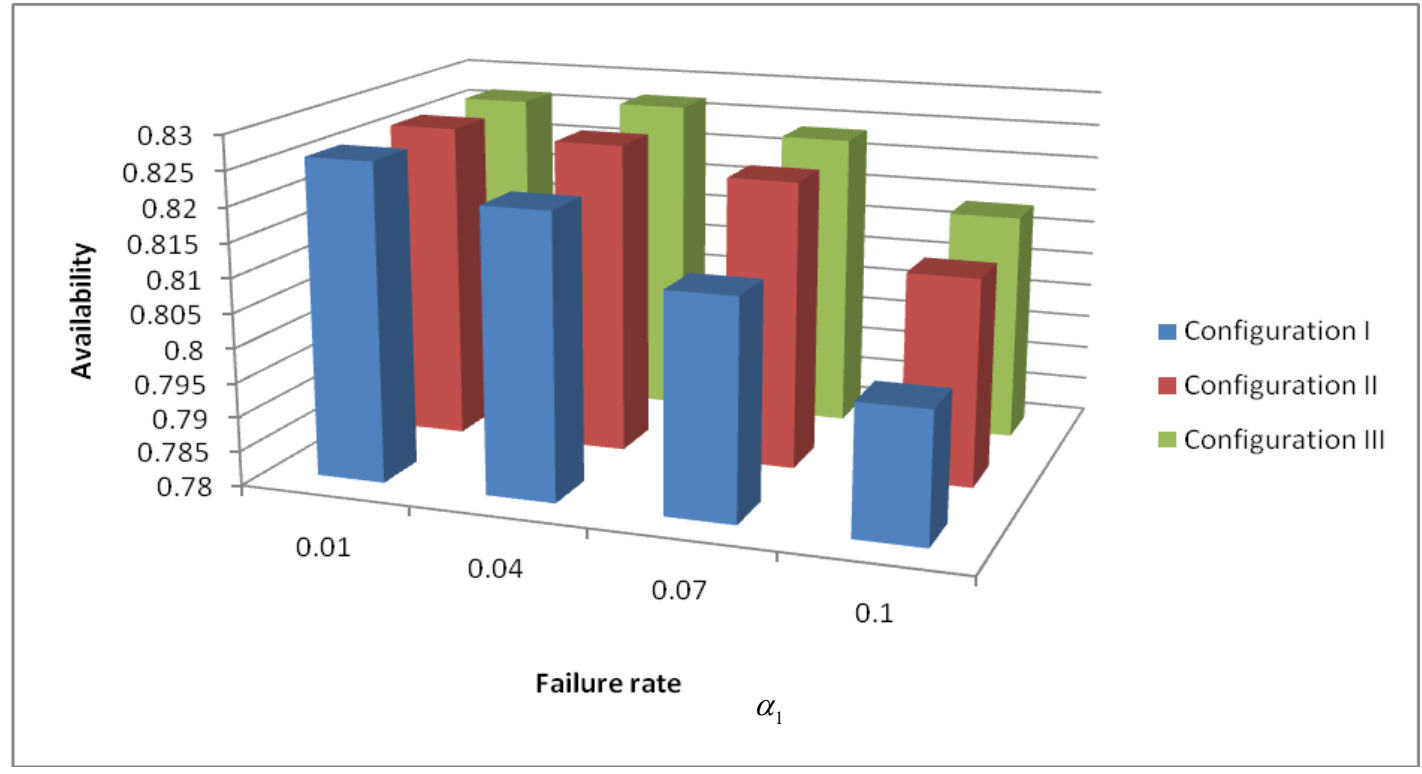

Fig. 1: Availability Against $\alpha_{1}$

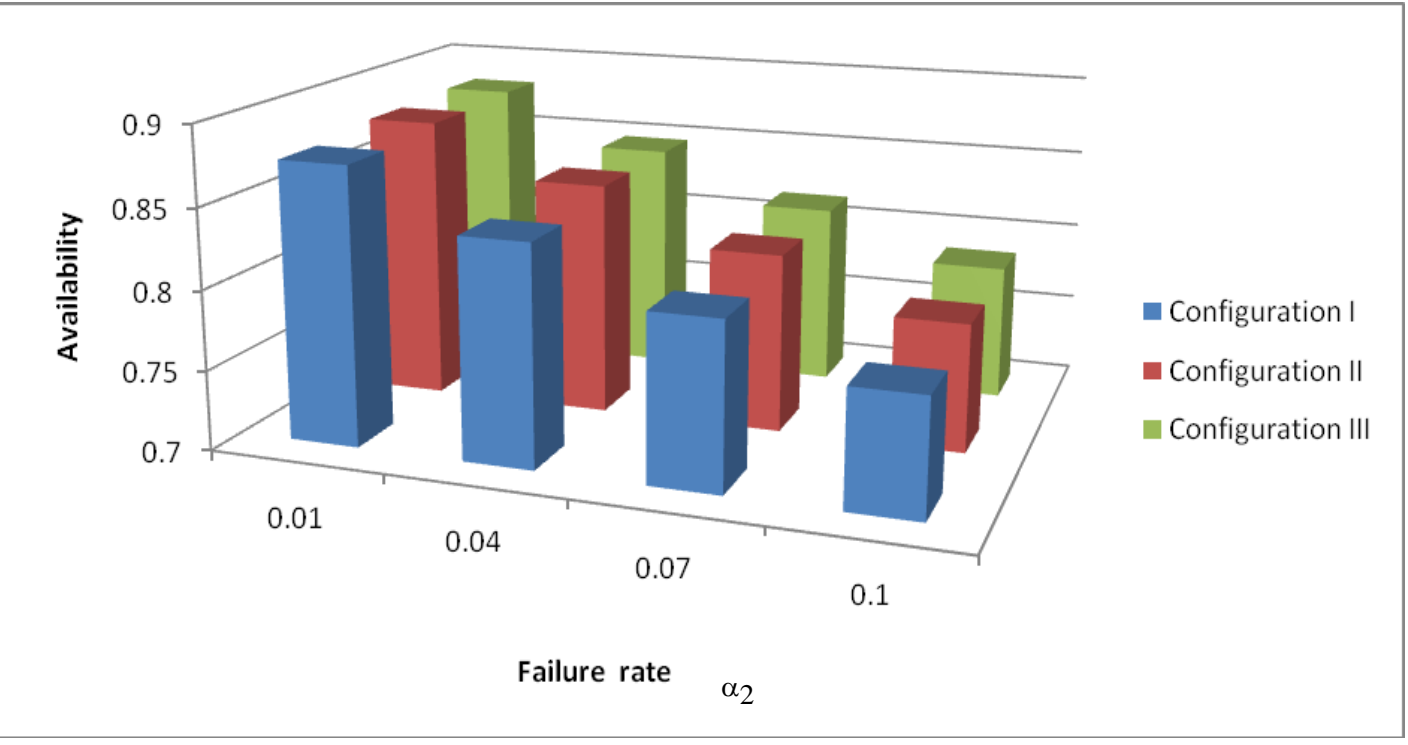

Fig. 2: Availability Against ${ }^{\alpha_{2}}$.

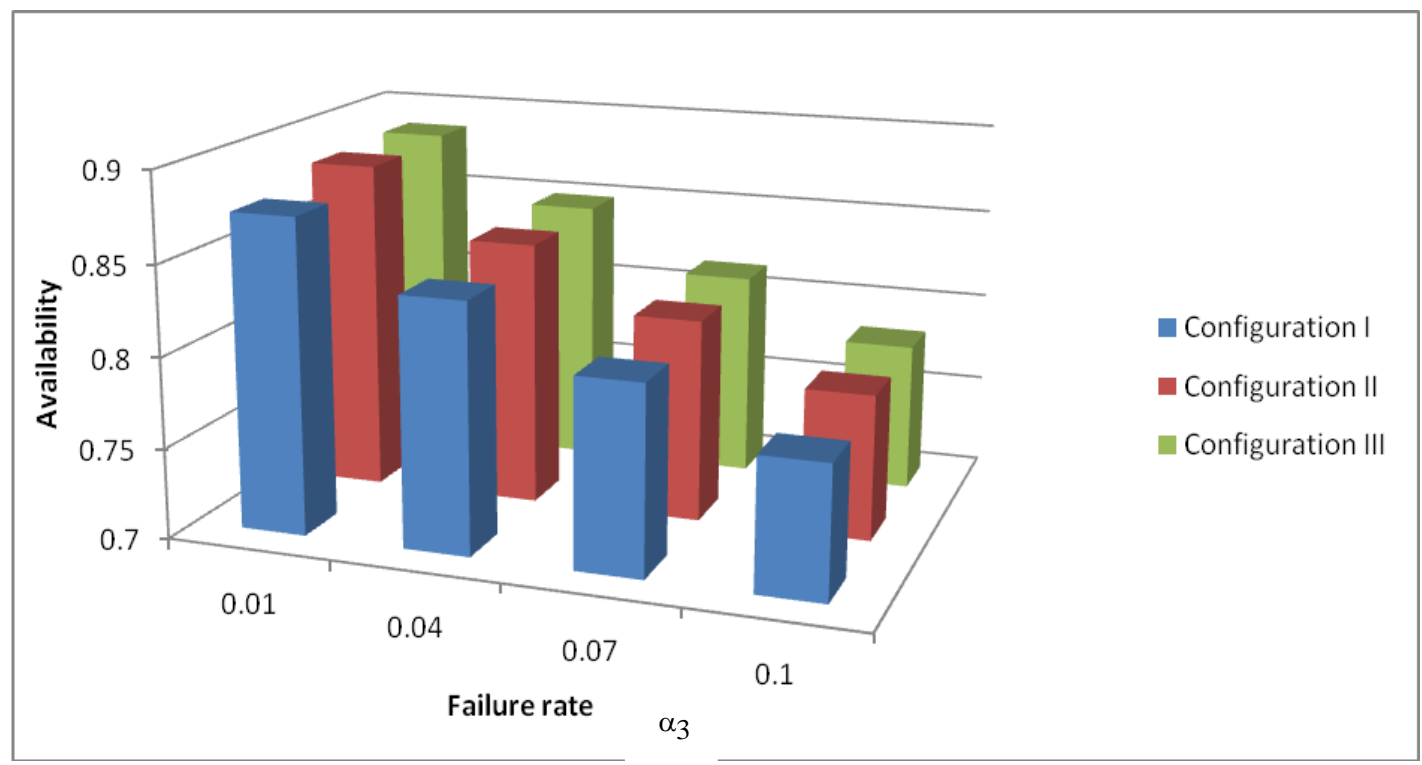

Fig. 3: Availability Against ${ }^{\alpha_{3}}$. 


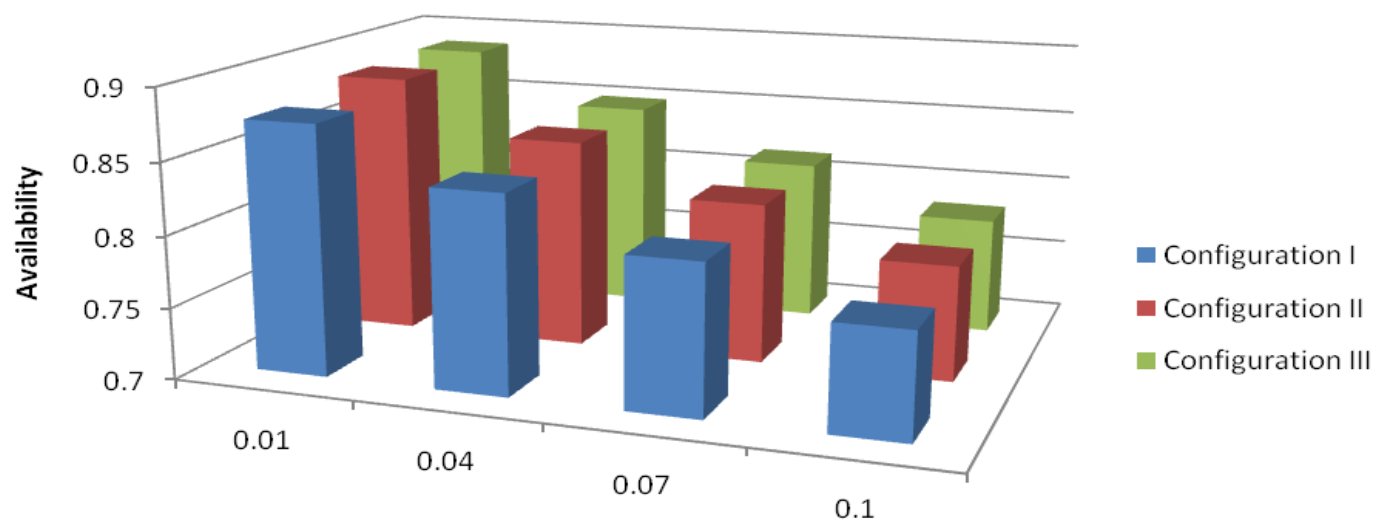

Failure rate $\alpha_{4}$

Fig. 4: Availability Against $\alpha_{4}$

From Figure $1-4$ as the failure rate increases from 0.01 to 0.1 , availability of each configuration decreases. However, at each level of failure, configuration III tends to have higher availability than the configurations I and II. Thus,

$\mathrm{A}_{\mathrm{V} 3}(\mathrm{t})>\mathrm{A}_{\mathrm{V} 2}(\mathrm{t})>\mathrm{A}_{\mathrm{V} 1}(\mathrm{t})$

The result presented in Figure 1 - 4 has shown that redundancy played an important role in increasing the system availability. The availability of such configurations can be enhanced by using highly redundant structural design of the units or subsystems. High system availabilities are system performance measures that play vital in the increase of the production volume and thus contributes towards profitability of the industry. In this analysis, Configuration III has four redundant units in subsystem A than configurations, I and II, hence has the highest availability.

\section{Conclusion}

In this paper, three dissimilar photovoltaic configurations are considered. Explicit expressions for the system availability for the three configurations were derived, and comparative analysis between the configurations was also performed graphically. From the analysis, we conclude that configuration III is better than the other configurations. The result shows that configuration with more redundancy than others has higher availability. Thus, the system designs incorporating redundancy affect our results.

\section{Acknowledgement}

The authors are grateful to the anonymous reviewers and handling editor for their constructive comments, which have helped to. Improved the manuscript.

\section{References}

[1] Abdulkadir M, Samosir A. S., Yatim A. H. M. (2013) "Modeling and Simulation of a Solar Photovoltaic System, Its Dynamics and Transient Characteristics in LABVIEW" International Journal of Power Electronics and Drive System (IJPEDS) Vol. 3, No. 2, pp. 185-192. https://doi.org/10.11591/ijpeds.v3i2.2422.

[2] Ajay Kumar, K. Garg and P.C. Tiwari (2014) Performance Modeling And Availability Analysis of Malt Screener System In A Brewery Plant International Journal of Latest Research in Science and Technology 3(2) 201-209

[3] Bastisdas, J.D.; Romas-Paja, C.A.; Franco, E.; Spagnuolo, Petrone G. (2013) Modeling of photovoltaic field in mismatching conditions by means of inflection voltages. In proceedings of Engineer- ing Applications (WAE) 2012 Workshop, Bogota, Columbia, 2-4 May 2012; pp. 1-6.

[4] Elhassan, Z.A.M.; Zain, M.F.M.; Sopian K. Abass (2012). Building integrated photovoltaics (BIPV) module in urban housing in Khartoum: Concept and design, International Journal of Physical Sciences 7, 487-494.

[5] Enslin J. H. R., Wolf, M. S., Snyman,D. B. and W. Swiegers. (1997) "Integrated photovoltaic maximum power point tracking converter," IEEE Transactions on Industrial Electronics, vol. 44, no. 6, pp. 769-773. https://doi.org/10.1109/41.649937.

[6] Khatab, A., Nahas, N., and Nourelfath, M., (2009). Availbilty of kout-of-n: G systems with non identical components subject to repair priorities.Reliab. Eng. Syst. Safety. 94, 142-151 https://doi.org/10.1016/j.ress.2008.02.017.

[7] Ke, J.C. and Chu, Y.K. (2007). Comparative analysis of availability for a redundant repairable system. Applied Mathematics and Computation, $188, \quad$ pp 332-338 https://doi.org/10.1016/j.amc.2006.09.123.

[8] Mahmodian, M.S. Rahmani. R.: Taslimi. E. Mekhilef S. (2012) Step By Step Analyzing, Modeling and Simulation of Single and Double Array PV System in Different EnvironmentalVariability, Proceedings of International Conference on Future Environment and Energy, Singapore. 26-28:37-42

[9] Mokaddis, G.S., El Sherbeny, M.S. and Al-Esayey, Entesar.(2010). Compare between two unit cold standby and warm standby outdoor electric power systems in changing weather, Journal of Mathematics and Statistics, 6(1), 17-22 https://doi.org/10.3844/jmssp.2010.17.22.

[10] Mekhilef, S.; Saidur, R.; Safari, A. A review on solar energy use in industries. Renew. Sustain. Energies Rev. 2011, 15, 1777-1790. https://doi.org/10.1016/j.rser.2010.12.018.

[11] Quaschning., V. and Hanitsch, R. (1996) "Numerical simulation of current-voltage characteristics of photovoltaic systems with shaded solar cells," Solar Energy, vol. 56, no. 6, pp. 513-520, https://doi.org/10.1016/0038-092X(96)00006-0.

[12] Villalva. MG: Gazoli, J.R. (2009) Comprehensive Approach to Modeling and Simulation of Photovoltaic Arrays, IEEE Trans. $\begin{array}{lllll}\text { Power Electron. } & \text { 24: } 1198 \quad- & 1208\end{array}$ https://doi.org/10.1109/TPEL.2009.2013862.

[13] Wang, K,-H., Don, W,-L and Ke, J,-B. (2006). Comparison of reliability and availability between four systems with warm standby components and standby switching failures, Appl. Math. And Comput., Vol. 183, 1310-1322 https://doi.org/10.1016/j.amc.2006.05.161.

[14] Wang, K.H. and Chen, Y.-J. (2009). Comparative analysis of availability between three systems with general repair times, reboot delay and switching failures. Applied Mathematics and Computation, 215, 384-394. https://doi.org/10.1016/j.amc.2009.05.023.

[15] Wang, K,-H., Yen, T,-C. and Fang, Y,-C. (2012). Comparison of Availability between two systems with warm standby units and different imperfect coverage, Quality technology and quantitative management, 9(3), pp 265-282 https://doi.org/10.1080/16843703.2012.11673291.

[16] Yusuf, I. (2013). Comparison of some reliability characteristics between redundant systems requiring supporting units for their operation. Journal of Mathematical and Computational Sciences, 3(1), pp 216-232. 